\title{
Implementation of an AlGaN-based solar-blind UV four-quadrant detector
}

\author{
L. van Schalkwyk*, W.E. Meyer, J.M. Nel, F.D. Auret, P.N.M. Ngoepe \\ Department of Physics, University of Pretoria, Private bag X20, Hatfield, 0028, South Africa
}

\begin{abstract}
An AlGaN-based front illuminated intrinsically solar-blind ultraviolet four-quadrant Schottky detector was fabricated and characterized. A layered ohmic structure was deposited followed by a multi-step annealing method. Ultraviolet transmissive iridium oxide was used as the Schottky barrier material and formed by a two-step annealing method. Au contacts were deposited on the Schottky contacts and annealed. The detector was mounted onto a commercial chip carrier and wires were epoxy bonded from the ohmic and Au contacts to the carrier strips. The detector had an average ideality factor of $1.97 \pm 0.08$, a Schottky barrier height of $(1.22 \pm 0.07) \mathrm{eV}$, a reverse leakage current density of $(2.1 \pm 4) \mathrm{nA} / \mathrm{cm}^{2}$, a series resistance of $(120 \pm 30) \Omega$ and a free carrier concentration of $(1.6 \pm 0.3) \times 10^{18} \mathrm{~cm}^{-3}$. Spectral characterization on the photosensitive area of $7.3 \times 10^{-3} \mathrm{~cm}^{2}$ yielded a cut-off wavelength at $(275 \pm 5) \mathrm{nm}$ $(4.59 \mathrm{eV}$ to $4.23 \mathrm{eV})$ for each quadrant, corresponding to the absorption edge of a ( $46 \pm 3) \% \mathrm{Al}$ content AlGaN-based material. The detector had an average responsivity of $(28 \pm 2) \mathrm{mA} / \mathrm{W}$ and quantum efficiency of $(14 \pm 1) \%$ at 250 $\mathrm{nm}$. The ultraviolet-to-visible and near-infrared rejection ratio was between $10^{3}$ and $10^{5}$ for most of the quadrants. Characterization showed uniformity across the quadrants, proving the detector feasible for implementation in future ultraviolet-sensitive electro-optic devices.
\end{abstract}

Keywords: AlGaN, solar-blind, ultraviolet, iridium oxide, Schottky, detector, optoelectronic, UV-to-visible rejection ratio

PACS: 73.61.Ey, 78.20.-e, 85.30.De, 85.60.Dw, 85.60.-q, 78.20.Jq

\section{Introduction}

The Sun radiates over the entire ultraviolet (UV) spectrum, however, ozone in the Earth's atmosphere strongly absorbs wavelengths between $200 \mathrm{~nm}$ and 300 $\mathrm{nm}[1,2]$. Solar-blind UV detectors are sensitive only to wavelengths in the UV-C region (200 $\mathrm{nm}$ to $280 \mathrm{~nm}$ ) and therefore only respond to terrestrial sources radiating in this region [3].

UV research began in the latter half of the 19th century and the development of electro-optic systems for studying objects emitting in the UV region $(10 \mathrm{~nm}$ to $400 \mathrm{~nm}$ ) was stimulated after World War II, because of their military, industrial and scientific applications $[1,2,4]$. These systems and their components need to be robust, withstand UV radiation, and have good signalto-noise ratios $(\mathrm{S} / \mathrm{N})$. They also need to be compact, environmentally friendly and cost effective. However, tra-

\footnotetext{
${ }^{*}$ Corresponding author

Email address: Louwrens. VanSchalkwyk@up.ac.za (L. van Schalkwyk)
}

Preprint submitted to Physica B ditional electro-optics systems make use of sensors that consists of photomultiplier tubes (PMT) and Si-based detectors [5]. The wide range in wavelength response of these detectors requires expensive additional filters that result in added electronics to improve $\mathrm{S} / \mathrm{N}$, and $\mathrm{PMT}$ are needed for high photosensitivity which use high-voltage power supplies, resulting in bulky systems $[1,5]$.

Advances in material growth techniques and processing of group-III-nitrides resulted in an unique semiconductor material system, one being the ternary semiconductor $\mathrm{Al}_{x} \mathrm{Ga}_{1-x} \mathrm{~N}[6,7]$. The $\mathrm{AlGaN}$ semiconductor system offers a wide direct bandgap that is tuneable over a spectral range by varying the $\mathrm{Al}$ mole fraction (x) [5]. This allows detectors not to respond to certain (longer) wavelengths, making them intrinsically "blind" to specific wavelengths, eliminating the need for expensive filters in systems. Moreover, the III-nitride optoelectronic devices promise to have higher efficiencies, are environmentally friendly, robust and being compact, will diversify their application [7].

We investigated the implementation of an AlGaN-

August 27, 2013 
based solar-blind UV four-quadrant detector, after success in studying front illuminated intrinsically solarblind UV AlGaN-based Schottky photodiodes with iridium oxide $\left(\mathrm{IrO}_{2}\right)$ as the Schottky barrier material, and feasibility of wire bonding with the addition of Au contacts [3].

\section{Experimental procedure}

An $\mathrm{Al}_{0.45} \mathrm{Ga}_{0.55} \mathrm{~N}$-based (4.47 eV bandgap [8]) sample obtained from Technologies and Devices, Inc. was used for the fabrication and characterization of a front illuminated four-quadrant intrinsically solar-blind UV Schottky detector. Sample preparation consisted of chemical degreasing, followed by wet chemical etching $[9,10]$. Fabrication was done by performing depositions through three different metal contact masks defining the ohmic, Schottky and Au contacts as illustrated in Fig. 1. A layered ohmic structure of $\mathrm{Ti} / \mathrm{Al} / \mathrm{Ni} / \mathrm{Au}$

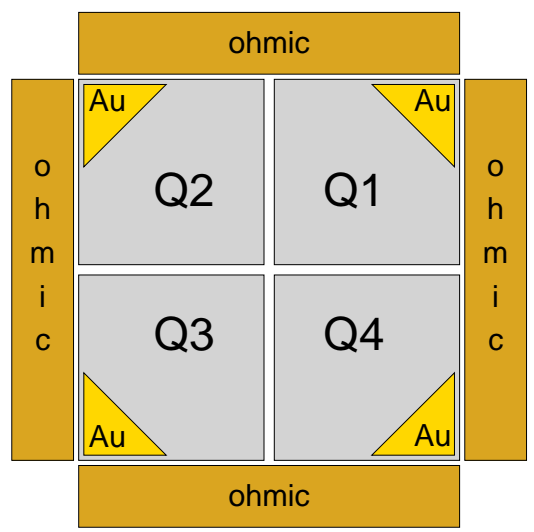

Figure 1: Schematic illustration of the deposited metal contacts forming a four-quadrant detector.

(300/1800/400/1500 ^) was deposited [11]. The ohmic contacts were multi-step annealed under an argon ambient for $3 \mathrm{~min}$ at $400{ }^{\circ} \mathrm{C}, 20 \mathrm{~s}$ at $700{ }^{\circ} \mathrm{C}, 30 \mathrm{~s}$ at 830 ${ }^{\circ} \mathrm{C}$ and $30 \mathrm{~s}$ at $900{ }^{\circ} \mathrm{C}[11,12]$. Square $(0.9 \times 0.9) \mathrm{mm}$, $50 \AA$ A-thick Ir contacts were deposited as Schottky contacts. The Schottky diodes were two-step annealed in $\mathrm{O}_{2}$ ambient for $30 \mathrm{~min}$ at both $600{ }^{\circ} \mathrm{C}$ and $730{ }^{\circ} \mathrm{C}$ to form the more UV transmissive $\mathrm{IrO}_{2}$ Schottky photodiodes [13-15]. Thereafter, $0.8 \times 10^{-3} \mathrm{~cm}^{2} 1500 \AA$-thick triangular Au contacts were deposited on top of the outermost corners of the Schottky contacts and annealed in $\mathrm{O}_{2}$ ambient for $10 \mathrm{~min}$ at $500{ }^{\circ} \mathrm{C}$. The detector was mounted onto a commercial chip carrier and wires were epoxy bonded from the ohmic and Au contacts to the carrier strips using EPO-TEK H20E silver-filled epoxy.
Each quadrant was characterized with an optoelectronic system [3]. Measurements were made by placing the probes on the chip carrier strips that were epoxy wire bonded to the corresponding contacts. Electrical characterization was performed on the $8.1 \times 10^{-3}$ $\mathrm{cm}^{2}$ Schottky contacts and consisted of current-voltage $(I-V)$ and capacitance-voltage $(C-V)$ measurements. The main parameters determined from the $I-V$ measurements were the ideality factors $(n)$, the Schottky barrier height $\left(\phi_{\mathrm{B}}\right)$, the reverse leakage current density $\left(J_{\mathrm{R}}\right)$ at $-1 \mathrm{~V}$ bias and series resistance $\left(R_{\mathrm{S}}\right)$. The free carrier concentration $\left(N_{\mathrm{D}}\right)$ was determined from $C-V$ measurements.

Spectral characterization included the cut-off wavelength $\left(\lambda_{\text {cut-off }}\right)$, responsivity $\left(\mathcal{R}_{\lambda}\right)$, quantum efficiency $\left(\eta_{\lambda}\right)$ at specific wavelengths and also the UV-to-visible and near-infrared (UV-to-VIS/NIR) rejection ratio of each quadrant with a photosensitive area of $7.3 \times 10^{-3}$ $\mathrm{cm}^{2}$. We calculated the UV-to-VIS/NIR rejection ratio as follows:

$$
J_{\mathrm{ph}}\left(\lambda_{s}\right) / J_{\mathrm{ph}}\left(\lambda \geq \lambda_{s}\right)=\frac{J_{\mathrm{ph}}\left(\lambda_{s}\right)}{\left|J_{\mathrm{ph}}\left(\lambda_{i}\right)-J_{\mathrm{ph}}\left(\lambda_{d}\right)\right|}
$$

Here, we first measured the dark photocurrent density (PCD) or noise $\left(J_{\mathrm{ph}}\left(\lambda_{d}\right)\right)$ of each quadrant for a chosen wavelength range, followed by measuring the illuminated PCD $\left(J_{\mathrm{ph}}\left(\lambda_{i}\right)\right)$ of each quadrant for the same wavelength range. The PCD at a specified wavelength $\left(J_{\mathrm{ph}}\left(\lambda_{s}\right)\right)$ was then divided by the illuminated PCD after subtracting the dark PCD at the corresponding wavelengths. The spectral PCD measured in the visible to near-infrared region was done using a $30 \mathrm{~W}$ tungstenhalogen lamp mounted directly onto a Czerny-Turner type monochromator [3]. A $400 \mathrm{~nm}$ cut-on wavelength order sorting filter was also added to aid in eliminating higher-order diffraction effects.

\section{Results and discussion}

\subsection{Electrical Characterization}

Dark $I-V$ and $C-V$ measurements were made on each quadrant before any UV illumination. The $I-V$ characteristics of each quadrant are presented in Fig. 2. The values of the parameters extracted from the electrical characteristics of the quadrants are listed in Table 1.

Electrical characterization resulted in an average ideality factor of $1.97 \pm 0.08$, a Schottky barrier height of $(1.22 \pm 0.07) \mathrm{eV}$, a reverse leakage current density of $(2.1 \pm 4) \mathrm{nA} / \mathrm{cm}^{2}$, a series resistance of $(120 \pm 30) \Omega$ and a free carrier concentration of $(1.6 \pm 0.3) \times 10^{18} \mathrm{~cm}^{-3}$. 


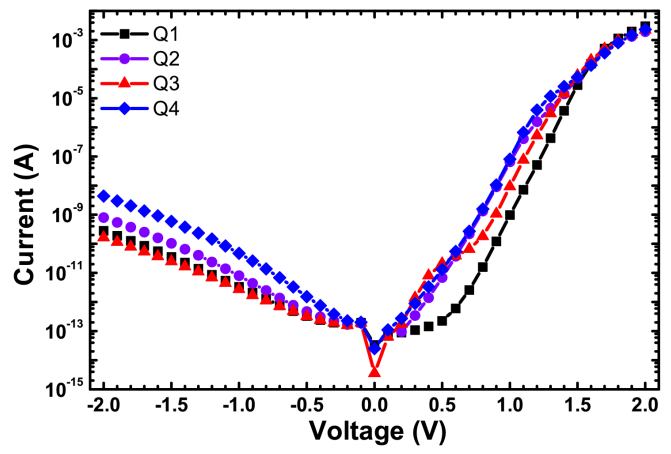

Figure 2: I-V characteristics for each quadrant of the front illuminated four-quadrant intrinsically solar-blind UV Schottky detector.

Table 1: Ideality factor, Schottky barrier height, reverse leakage current density, series resistance and free carrier concentration of each quadrant of the front illuminated four-quadrant intrinsically solarblind UV Schottky detector, together with the overall average.

\begin{tabular}{|c||c|c|c|c|c|}
\hline Quadrant & $n$ & $\begin{array}{c}\phi_{\mathrm{B}} \\
(\mathrm{eV})\end{array}$ & $\begin{array}{c}J_{\mathrm{R}} \text { at }-1 \mathrm{~V} \\
\left(\mathrm{nA} / \mathrm{cm}^{2}\right)\end{array}$ & $\begin{array}{c}R_{\mathrm{S}} \\
(\Omega)\end{array}$ & $\begin{array}{c}N_{\mathrm{D}} \\
\left(10^{18} \mathrm{~cm}^{-3}\right)\end{array}$ \\
\hline Q1 & 1.92 & 1.30 & 0.5 & 90 & 2.0 \\
\hline Q2 & 2.09 & 1.15 & 1.1 & 150 & 1.7 \\
\hline Q3 & 1.91 & 1.24 & 0.4 & 140 & 1.3 \\
\hline Q4 & 1.95 & 1.18 & 6.5 & 110 & 1.5 \\
\hline \hline Average & 1.97 & 1.22 & 2.1 & 120 & 1.6 \\
\hline
\end{tabular}

Comparing the parameters to that of a previous study done by the same authors [3], we found that the average ideality factor degraded by approximately $20 \%$ from 1.57 to 1.97 , a $3 \%$ higher Schottky barrier height from $1.19 \mathrm{eV}$ to $1.22 \mathrm{eV}$ and an $16 \%$ increase in series resistance from $100 \Omega$ to $120 \Omega$. The degradation in ideality factor and higher Schottky barrier height could be a result of the epoxy bonding process, by which some of the epoxy may have made direct contact to the semiconductor material. The addition of the epoxy and connecting wires would have contributed to an increased series resistance. The average reverse leakage current density greatly improved by almost a factor of 25 from $49 \mathrm{nA} / \mathrm{cm}^{2}$ to $2.1 \mathrm{nA} / \mathrm{cm}^{2}$, even with the free carrier concentration being almost $13 \%$ more than the $1.4 \times 10^{18} \mathrm{~cm}^{-3}$ found in [3]. This can either be attributed to the use of an optimized layered ohmic structure together with an improved multi-step annealing method, the proper formation of $\mathrm{IrO}_{2}$ through the two-step annealing method at appropriate temperatures or by annealing the Au contacts.

\subsection{Spectral Characterization}

The dark $I-V$ and $C-V$ measurements were followed by spectral characterization for wavelengths ranging

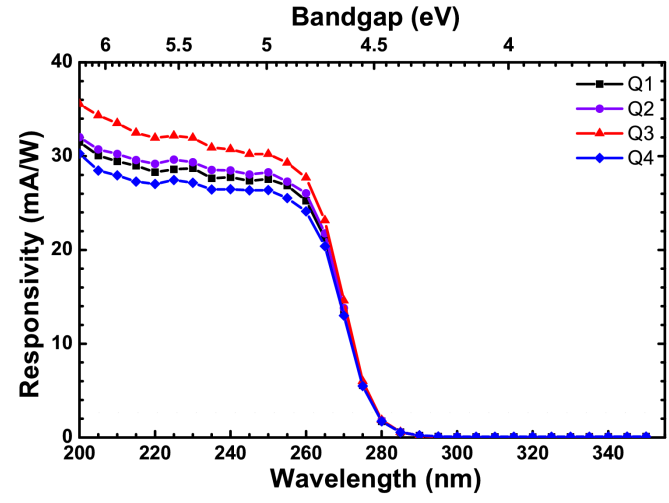

Figure 3: Spectral responsivities for each quadrant of the front illuminated four-quadrant intrinsically solar-blind UV Schottky detector at zero biasing.

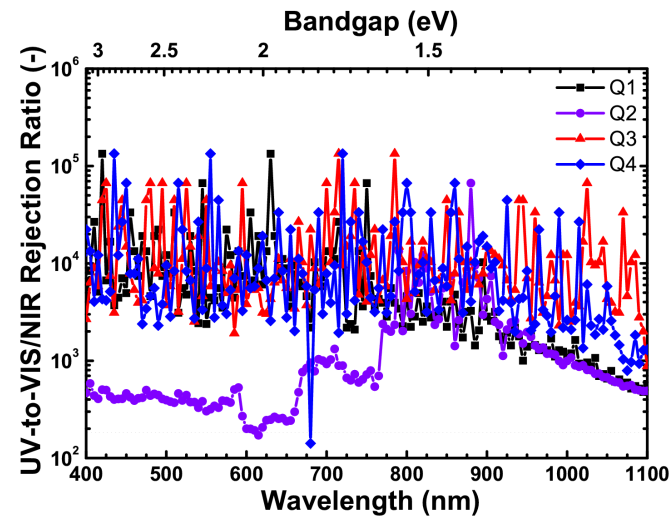

Figure 4: Spectral UV-to-visible and near-infrared rejection ratios for each quadrant of the front illuminated four-quadrant intrinsically solar-blind UV Schottky detector at zero biasing with respect to the responsivity at $250 \mathrm{~nm}\left(J_{\mathrm{ph}}\left(\lambda_{s}\right) / J_{\mathrm{ph}}(\lambda \geq 400)\right)$.

from $200 \mathrm{~nm}$ to $350 \mathrm{~nm}$. Fig. 3 shows the spectral responsivities measured for each quadrant at zero bias.

Fig. 4 was obtained by first measuring the dark PCD of each quadrant for wavelengths ranging from $400 \mathrm{~nm}$ to $1100 \mathrm{~nm}$, followed by measuring the illuminated PCD for the same wavelength range. The PCD measured at $250 \mathrm{~nm}$ was then divided by the illuminated PCD after subtracting the dark PCD. The parameters extracted from the spectral characteristics are listed in Table 2.

A cut-off wavelength at $(275 \pm 5) \mathrm{nm}$ for each quadrant was observed, corresponding to the absorption edge of an AlGaN-based material having a $(46 \pm 3) \% \mathrm{Al}$ content with a bandgap ranging from $4.59 \mathrm{eV}$ to $4.23 \mathrm{eV}$ [8]. This agreed with the $\mathrm{Al}_{0.45} \mathrm{Ga}_{0.55} \mathrm{~N}$-based sample supplied. An average responsivity of $(28 \pm 2) \mathrm{mA} / \mathrm{W}$ and quantum efficiency of $(14 \pm 1) \%$ at $250 \mathrm{~nm}$ were 
Table 2: Cut-off wavelength, responsivity, quantum efficiency at 250 $\mathrm{nm}$ and the UV-to-visible and near-infrared rejection ratio of each quadrant of the front illuminated four-quadrant intrinsically solarblind UV Schottky detector, together with the overall average.

\begin{tabular}{|c||c|c|c|c|}
\hline Quadrant & $\begin{array}{c}\lambda_{\text {cut-off }} \\
(\mathrm{nm})\end{array}$ & $\begin{array}{c}\mathcal{R}_{250} \\
(\mathrm{~mA} / \mathrm{W})\end{array}$ & $\begin{array}{c}\eta_{250} \\
(\%)\end{array}$ & $\begin{array}{c}\text { UV-to-VIS/NIR } \\
J_{\mathrm{ph}}\left(\lambda_{s}\right) / J_{\text {ph }}(\lambda \geq 400)\end{array}$ \\
\hline Q1 & 275 & 28 & 14 & $10^{2}$ to $10^{5}$ \\
\hline Q2 & 275 & 28 & 14 & $10^{2}$ to $10^{4}$ \\
\hline Q3 & 275 & 30 & 15 & $10^{2}$ to $10^{5}$ \\
\hline Q4 & 275 & 26 & 13 & $10^{2}$ to $10^{5}$ \\
\hline \hline Average & 275 & 28 & 14 & $10^{2}$ to $10^{5}$ \\
\hline
\end{tabular}

found. The UV-to-VIS/NIR rejection ratio was between $10^{3}$ and $10^{5}$ for most of the quadrants across the considered range.

Comparing some of the parameters again to that found in a previous study done by the same authors [3], we found that both the average responsivity and quantum efficiency almost halved, from $52 \mathrm{~mA} / \mathrm{W}$ to 28 $\mathrm{mA} / \mathrm{W}$ and $23 \%$ to $14 \%$. The samples used may have contributed to the latter, because they originated each from wafers grown differently.

\section{Summary \& Conclusions}

A front illuminated AlGaN-based four-quadrant intrinsically solar-blind UV Schottky detector was fabricated by depositing through three different metal contact masks defining the ohmic, Schottky and Au contacts. The detector was then mounted onto a commercial chip carrier and silver-filled epoxy was used to perform wire bonding from the ohmic and $\mathrm{Au}$ contacts to the carrier strips.

The fabrication technique resulted in that the detector had a $20 \%$ average degradation in ideality factor, a $3 \%$ higher Schottky barrier height, a $16 \%$ increase in series resistance. The average reverse leakage current density, however, improved by a factor of 25 .

Every quadrant had a cut-off wavelength at $(275 \pm 5)$ $\mathrm{nm}$, corresponding to a bandgap ranging from $4.59 \mathrm{eV}$ to $4.23 \mathrm{eV}$. The detector had an average responsivity of $(28 \pm 2) \mathrm{mA} / \mathrm{W}$ and quantum efficiency of $(14 \pm 1) \%$ at $250 \mathrm{~nm}$. The high UV-to-VIS/NIR rejection ratios of between $10^{3}$ and $10^{5}$ proved the detector to be intrinsically solar-blind for wavelengths ranging for $400 \mathrm{~nm}$ to $1100 \mathrm{~nm}$.

Even-though the Schottky contacts were not ideal and the quadrants had relatively lower responsivities, and subsequently lower quantum efficiencies, they were almost identical in their characteristics. This allowed for the completion of a joint initiative with the Sensor Science \& Technology Competence Area of CSIR's Mate- rials Science and Manufacturing (MSM) Unit, who successfully mounted the four-quadrant detector in a housing integrated with electronics and used UV optics to demonstrate a working UV-sensitive electro-optic device.

The fact that the detector was successfully mounted onto a commercial chip carrier, epoxy wire bonded for easy electronic integration, characterized and yielded uniformity across the quadrants, makes the implementation of an AlGaN-based solar-blind UV four-quadrant detector feasible for future UV-sensitive electro-optic devices.

\section{Acknowledgements}

The authors wish to thank the Sensor Science \& Technology Competence Area of CSIR's MSM Unit for integrating the four-quadrant detector with UV optics to demonstrate the UV-sensitive electro-optic device. This work is based upon research supported by the Technology Innovation Agency (TIA) and the National Research Foundation (NRF). Disclaimer: Any opinion, findings and conclusions or recommendations expressed in this material are those of the author(s) and therefore the NRF does not accept any liability in regard thereto.

\section{References}

[1] M. Razeghi, A. Rogalski, J. Appl. Phys. 79 (10) (1996) 7433.

[2] Y. A. Goldberg, Semicond. Sci. Technol. 14 (7) (1999) 41-60.

[3] L. van Schalkwyk,W. E. Meyer, F. D. Auret, J. M. Nel, P. N. M. Ngoepe, M. Diale, Physica B: Condens. Matter 407 (10) (2012) 1529-1532.

[4] E. Monroy, F. Omnès, F. Calle, Semicond. Sci. Tech. 18 (4) (2003) R33-R51.

[5] E. Muñoz, Phys. Status Solidi B 244 (8) (2007) 2859-2877.

[6] M. Razeghi, R. McClintock, J. Crys. Growth 311 (10) (2009) 3067-3074.

[7] M. Razeghi, IEEE Photonics Journal 3 (2) (2011) 263-267.

[8] F. Omnès, N. Marenco, B. Beaumont, P. de Mierry, E. Monroy, F. Calle, E. Muñoz, J. Appl. Phys. 86 (9) (1999) 5286.

[9] M. Diale, F. D. Auret, N. G. van der Berg, R. Q. Odendaal,W. D. Roos, Appl. Surf. Sci. 246 (1-3) (2005) 279-289.

[10] P. J. Janse van Rensburg, F. D. Auret, V. S. Matias, A. Vantomme, Physica B: Condens. Matter 404 (22) (2009) 4411-4414.

[11] B. Jacobs, J. Cryst. Growth 241 (1-2) (2002) 15-18.

[12] Q. Feng, L.-M. Li, Y. Hao, J.-Y. Ni, J.-C. Zhang, Solid State Electron 53 (9) (2009) 955-958.

[13] J. K. Kim, H. W. Jang, C. M. Jeon, J. L. Lee, Appl. Phys. Lett. 81 (24) (2002) 4655.

[14] B. R. Chalamala, Y. Wei, R. H. Reuss, S. Aggarwal, S. R. Perusse, B. E. Gnade, R. Ramesh, J Vac. Sci. Technol. B 18 (4) (2000) 1919.

[15] R. K. Kawar, P. S. Chigare, P. S. Patil, Appl. Surf. Sci. 206 (2003) 90-101. 